\title{
Especialização produtiva primária e meio ambiente em período recente na Amazônia
}

\section{Primary productive expertise and environment in the amazonian recent period}

José Raimundo Trindade - Professor do Programa de Pós-Graduação em Economia (PPGE) da Universidade Federal do Pará (UFPA). Doutor em Desenvolvimento Econômico pelo Programa de Pós-Graduação em Desenvolvimento Econômico da Universidade Federal do Paraná. E-mail: jrtrindade@ufpa.br.

Wesley Pereira de Oliveira - Mestre em Economia pelo PPGE da UFPA; doutorando no Programa de Pós-Graduação em Economia da Universidade de Brasília (UnB). Bolsista Assistente de Pesquisa IV da Assessoria Técnica da Presidência do Instituto de Pesquisa Econômica Aplicada (Ipea). E-mail: wpoeconomia@yahoo.com.br

\section{Resumo}

Este trabalho analisa a participação das exportações da região amazônica na pauta nacional de exportação de produtos básicos e sua relação com as questões ambientais da região, demonstrando a contradição entre sustentabilidade econômica e ambiental, claramente visível na relação entre superávits da balança comercial e avanço do desmatamento na Amazônia.

\begin{abstract}
This paper makes effort to analyze the following aspects: i) Amazon's exports share in the Brazilian commodities exports and ii) its relationship with environmental issue in Amazon. As results, we show the paradox between economic and environmental sustainability which is clearly noticed between trade balance surplus and the increasing deforestation in the Amazon.
\end{abstract}

\section{Palavras-chave}

Amazônia. Exportação. Desmatamento.

\section{Keywords}

Amazon. Exports. Deforestation. 


\section{INTRODUÇÃO}

Ora, esta circunstância, este afrouxamento das atividades distendidas numa faixa dispersiva, a par de outras anomalias [...] contribui sobremaneira para o estacionamento da sociedade que ali se agita no afogado das espessuras, esterilmente - sem destino, sem tradiçoes e sem esperanças - num avançar ilusório em que volve monotonamente ao ponto de partida, como as 'estradas' tristonhas dos seringais...

Euclides da Cunha, 1906

O século XX da história econômica amazônica começa em grande estilo, com exponencial crescimento do setor exportador de borracha e substanciais alterações sociais e demográficas, tanto que o produto chegou a praticamente se equiparar ao café na balança exportadora brasileira, com 40\% de participação em 1910. Foi também o momento de maior crescimento urbano das duas principais cidades amazônicas, Belém e Manaus. Foi a Belle Époque.

Com a decadência da economia gomífera ainda no final da primeira década do século XX, a região entra em total marasmo por mais de vinte anos (LEAL, 2010; MENDES, 1958; PANDOLFO, 1994; SANTOS, 1980). Só a partir da década de 40 a atenção do governo central volta-se para a região, seja no segundo ciclo da borracha durante a Segunda Guerra Mundial, seja a partir de 1946 com a inserção do artigo 199 na Carta Constitucional.

O referido artigo surgiu por conta da pressão de parlamentares da Amazônia que reivindicavam a inserção de um instrumento constitucional que garantisse maior atenção do governo federal para a região. A partir desse artigo, tornava-se obrigatória a elaboração de um plano de valorização econômica da Amazônia. Diz o artigo 199: "Na execução do plano de valorização econômica da Amazônia, a União aplicará, durante, pelo menos, vinte anos consecutivos, quantia não inferior a três por cento da sua renda tributária".

Como fruto da discussão que se seguiu, em 1953 foi criada a Superintendência do Plano de Valorização Econômica da Amazônia (SPVEA) - a primeira tentativa de planejamento do desenvolvimento regional da Amazônia.

Como acentua Marques (2007), mais do que inovação no que diz respeito ao planejamento regional, a SPVEA trazia a ideia de que a retomada econômica da região não passaria mais pelo extrativismo. No mesmo ano de extinção do referido órgão, em 1966, outro é criado em seu lugar, a Superintendência de Desenvolvimento da Amazônia (SUDAM). A partir desse momento, de acordo com o discurso do governo militar de modernizar a economia brasileira, conforme ressalta Brito (1998), a Amazônia é tida como centro de concessão de incentivos e isenções visando atrair o empresariado para a exploração econômica da região. 
Desde então, a expansão econômica capitalista da Amazônia deu-se por via de três formatos básicos distintos: a implantação de grandes projetos na área da mineração, a criação da Zona Franca de Manaus e a exploração agropecuária e madeireira centrada no latifúndio, gerando forte concentração fundiária e pouco desenvolvimento.

Em período recente, a região tem a cada ano ganhado destaque por conta da extração mineral e da produção de soja. Esse quadro de expansão produtiva é acompanhado de intenso processo de desmatamento. Tem-se, então, o crescimento de atividades minerárias e agrárias de um lado e, de outro, o aumento da devastação de recursos florestais.

Estendendo a discussão da atividade primária ao âmbito nacional, observase recentemente que os produtos básicos estão cada vez mais presentes na pauta de exportação do país. Isso retoma o debate ocorrido a partir de 1930, no qual a proposta do governo e de boa parte do empresariado urbano daquela época abraçava a industrialização como meio de desenvolver o país, buscando superar a característica agrário-exportadora da economia brasileira, vista como a causa do atraso em que se encontrava o país. Junta-se a isso o ideário segundo o qual, para se desenvolver, o país precisa produzir e exportar mais produtos com valor agregado e menos produtos básicos, caso deseje o crescimento sustentado de sua economia e um lugar ao sol no cenário mundial.

Com o comportamento do setor exportador brasileiro em anos recentes, o país desponta no cenário mundial como grande produtor de commodities e/ou produtos primários - soja, carne e minério de ferro, principalmente. Há, então, uma preocupação quanto ao diferencial de crescimento do setor industrial, com elaboração de produtos com maior valor agregado, em relação ao setor exportador de produtos básicos Nesse contexto, a Amazônia tem relevância no cenário nacional como região exportadora de produtos primários, com destaque para produtos da extração mineral (minério de ferro, principalmente), boi vivo e, na zona fronteiriça com o Centro-Oeste, especialmente a área de contiguidade entre o Mato Grosso e o Pará, ganha relevância a produção de soja.

Este trabalho analisa os seguintes aspectos: i) participação das exportações da região amazônica na pauta nacional de exportação de produtos básicos e ii) relação das exportações com a problemática ambiental, demonstrando a contradição entre sustentabilidade econômica e ambiental, claramente visível na relação entre superávits da balança comercial e avanço do desmatamento na Amazônia. Está divido em cinco partes. Além desta introdução, na segunda seção a metodologia é apresentada, sendo sucedida por uma exposição sobre o setor 
exportador da Amazônia e do Brasil e sucinta análise do desmatamento, já na quarta parte os resultados são apresentados. Finalmente, a quinta seção traz as conclusões.

Os dados utilizados para discussão da especialização do setor exportador considerou o conceito de fator agregado em duas classes gerais: produtos básicos e produtos industrializados. Utilizou-se, para diferenciação entre as duas classes,os critérios definidos pelo Ministério do Desenvolvimento, Indústria e Comércio Exterior (MDIC):

a) Produtos básicos: produtos de baixo valor, normalmente intensivos em mão de obra, cuja cadeia produtiva é simples e que sofrem poucas transformações. Por exemplo, minério de ferro, grãos, agricultura, etc.

b) Produtos industrializados: dividem-se em semimanufaturados e manufaturados, uma vez mais considerando o grau de transformação, onde: i) semimanufaturado é o produto que passou por alguma transformação, porém de baixa tecnologia, por exemplo: suco de laranja congelado e couro; e ii) manufaturado é o produto normalmente de maior agregação tecnológica, com alto valor agregado, tipo televisor, chip de computador, automóvel, CD com programa de computador, etc.

Com base no conceito de fator agregado, procurou-se comparar os dados da Amazônia com os do Brasil. Mas, como estes não são encontrados de forma agrupado para a região amazônica, reunimos e tratamos as informações necessárias dos noves estados que compõem a região. Os dados agrupados acabaram por revelar que o esforço exportador na região está concentrado em somente dois estados: Pará e Mato Grosso. Em 2010, as exportações dos dois estados corresponderam a cerca de $80 \%$ do que a Amazônia exportou para outros países, razão pela qual concentraremos análise nesses dois estados.

\section{EXPORTAÇÃO DE PRODUTOS PRIMÁRIOS E A QUESTÃO AMBIENTAL}

Nesta seção, tratar-se-á da balança comercial da Amazônia e do Brasil, destacando-se o desempenho das exportações por fator agregado e detalhando-se alguns principais produtos comercializados com o resto do mundo. Trata-se aqui também da questão ambiental da Amazônia, enfatizando-se o desmatamento.

\subsection{O SETOR EXPORTADOR BRASILEIRO}

A balança comercial brasileira apresenta comportamento variado nas últimas duas décadas. Superavitária no começo dos anos 90 e, de 1995 a 2000, 
deficitária. A partir daí o que se observa é superávit e crescimento considerável do saldo comercial, com as exportações crescendo em ritmo mais acelerado que as importações. Chegou ao pico em 2006, com saldo de US $\$ 46,5$ bilhões, diminuindo o ritmo depois disso.

Dos destaques dos produtos básicos, o minério de ferro é o principal item da pauta de exportação, conforme evidenciado na Tabela 1 com os principais produtos exportados pelo país em 2010.

A soja também é outro importante produto. E, mesmo não estando (ainda) na lista, a carne bovina é outro item em franca ascensão. Em 2010, o Brasil exportou US $\$ 4,8$ bilhões em carne bovina ( $80 \%$ sendo in natura). Vale ressaltar que o país é o maior exportador mundial de carne bovina.

Tabela 1. Principais produtos exportados pelo Brasil (2010).

\begin{tabular}{l|r}
\hline \multicolumn{1}{c|}{ Descrição NCM } & \multicolumn{1}{c}{ US\$ (mil) } \\
\hline Minérios de ferro não aglomerados e seus concentrados & 21.353 .878 \\
\hline Óleos brutos de petróleo & 16.293 .240 \\
\hline Outros grãos de soja, mesmo triturados & 11.035 .210 \\
\hline Açúcar de cana, em bruto & 9.306 .851 \\
\hline Minérios de ferro aglomerados e seus concentrados & 7.558 .004 \\
\hline Café não torrado, não descafeinado, em grão & 5.181 .628 \\
\hline Outros & 131.186 .474 \\
\hline Total & 201.915 .285 \\
\hline
\end{tabular}

Fonte: MDIC (2011).

Como destacam Belluzzo e Almeida (2011), os "resultados da balança comercial mostram uma descomunal aceleração do déficit da indústria de transformação", com paulatino reforço da pauta primário-exportadora, como se evidenciam nos indicadores expostos mais a frente. Por outro lado, essa pauta primário-exportadora é fortemente concentrada na região amazônica, com óbvios elementos de impactos ambientais, especialmente focados no desmatamento, como se poderá observar na seção quatro deste artigo.

\subsection{O SETOR EXPORTADOR DA AMAZÔNIA}

Como não é objetivo aqui detalhar a balança comercial de todos os estados, uma vez que a maioria tem pequena participação na pauta de exportação, dois deles são enfatizados, a saber, Pará e Mato Grosso, pois são os dois maiores 
exportadores da Amazônia. Os dois estados ocupam a segunda e a terceira colocação, respectivamente, em termos de saldo comercial entre os estados brasileiros, ficando atrás apenas de Minas Gerais (dados referentes a 2010).

\subsubsection{Minério, gado e madeira: a pauta de exportações do Pará e o rastilho do desmatamento}

Na segunda metade do século passado, a economia do estado passou por forte processo de inserção do capital internacional, momento em que foram instaladas na região grandes plantas industriais de extração mineral, os denominados "grandes projetos mineradores". Segundo Trindade (2001), as décadas de 70 e 80 presenciaram o desenvolvimento dos empreendimentos mineiros no Estado do Pará, inseridos na estratégia assumida pelos governos militares, ainda na segunda metade da década de 70, de buscar relativa complementaridade da base industrial nacional. Esse processo teve início no II Plano Nacional de Desenvolvimento (II PND - 1975/79), durante o governo Geisel, objetivando a implantação de programas que tinham como meta a produção de bens de capital e insumos básicos.

Os interesses do Estado nacional em torno da instalação desses empreendimentos foram entre outras coisas: (i) gerar divisas visando ao equacionamento da crise cambial que começava a se esboçar e (ii) delinear o papel que a região passaria a desempenhar - ou seja, de fornecedora de bens primários ou semielaborados - para constituir-se no polo industrial do Centro-Sul ${ }^{1}$.

Deve-se, contudo, ressaltar que a lógica à qual se encontram vinculados tais interesses, pela sua magnitude, comportando escalas produtivas imensas, intensivas em capital e tecnologia compatíveis aos padrões internacionais, é determinada, em última instância, pelos circuitos de produção que têm seus centros de decisão nas empresas transnacionais do setor. A Companhia Vale é a principal beneficiária, como também o centro de acumulação de capital.

Os grandes projetos minerais estabeleceram uma nova disposição setorial na economia paraense, a partir da instalação das plantas de extração mineral de bauxita, hematita e dos poderosos interesses da Vale, em associação com capitais nacionais e estrangeiros. O Pará tornou-se o segundo produtor mineral do país, o que desencadeou modificações sociais e econômicas, particularmente em áreas sub-regionais, com relativas interferências sobre o comportamento da macro e da microeconomia do estado ${ }^{2}$. Apesar da queda de $16 \%$ da atividade de mineração em

1 A análise da integração subordinada da economia amazônica, seja ao polo econômico do Centro-Sul brasileiro, seja à economia global, tem sido fonte de estudos diversos. Vale destacar os estudos de Castro (2001), Bunker (2004) e Becker (2005).

2 Para análise de impactos tributários e suas repercussões sobre o desenvolvimento regional vale conferir Monteiro (2004). 
2009, provocada pela crise econômica mundial, o setor mineral ainda conseguiu exportar U\$ 4,9 bilhões contra U\$ \$,8 bilhões de 2008, o maior da história.

As exportações paraenses têm crescido substancialmente em anos recentes, mantendo a característica superavitária de sua balança comercial. Conforme mostram os dados do MDIC, em 1996 o Pará era o sétimo maior estado exportador, assumindo a nona posição em 2003. Deste último em diante, as exportações do estado só cresceram (com exceção da queda em 2009), e em 2010 as vendas ao resto do mundo já colocam o Pará como o sexto maior exportador do país, com US\$12,8 bilhões em venda ao exterior (com grandes chances de ultrapassar o Paraná nos próximos anos e assumir a quinta colocação); já as importações ficam próximas de US \$ 1,2 bilhão, encerrando o ano de 2010 com saldo de US\$ 11,6 bilhões.

Seria um cenário interessante e de conforto para o Pará não fossem as características intrínsecas a isso. Uma delas é a composição da pauta de exportação paraense, que é composta em mais de $70 \%$ por produtos básicos.

O principal produto da pauta de exportação paraense é o minério de ferro, que em 2010 representou mais de 50\% de tudo o que foi exportado pelo estado (ver Tabela 2) e mais de $30 \%$ da exportação nacional do produto. O aumento da demanda do produto no mercado internacional (mesmo com a elevação substancial do preço), principalmente da China, tem aumentado a exportação do produto. O citado país asiático, por exemplo, foi o destino de $50 \%$ de todo o minério de ferro vendido pelo Pará em 2010.

Tabela 2. Principais produtos exportados pelo Estado do Pará (2010).

\begin{tabular}{l|r}
\hline \multicolumn{1}{c|}{ Descrição NCM } & US\$ (mil) \\
\hline Minérios de ferro não aglomerados e seus concentrados & 6.900 .531 \\
\hline Alumina calcinada & 1.290 .617 \\
\hline Alumínio não ligado em forma bruta & 898.311 \\
\hline Outros minérios de cobre e seus concentrados & 701.513 \\
\hline Outros bovinos vivos & 618.207 \\
\hline Ferro fundido bruto não ligado, c/peso <=0.5\% de fósforo & 374.905 \\
\hline Outros & 2.051 .338 \\
\hline Total & 12.835 .420 \\
\hline
\end{tabular}

Fonte: MDIC (2011).

A exportação de boi vivo tem crescido recentemente e chegou a quase 5\% das exportações do estado do Pará em 2010 que é praticamente o único exportador do referido produto, com quase 98\% na pauta de exportação do Brasil. 
Portanto, os setores econômicos mais importantes da economia paraense são a mineração e o beneficiamento mineral, a pecuária e a extração da madeira, os quais acabam alavancando setores como serviços em geral, produção de alimentos, vestuário e construção civil, que colocaram o estado numa rota de crescimento econômico nas últimas décadas. No período de 1995 a $2007^{3}$, por exemplo, o crescimento acumulado do PIB paraense foi de $157,16 \%$, o que proporcionou um crescimento médio de $4,76 \%$ e consolidou taxas reais de crescimento da economia paraense bem acima da evolução do PIB acumulado brasileiro, que foi de 139,77\%, ou seja, 3,31\% em média.

Tal crescimento econômico centrado na produção e na exportação de bens básicos concorreu para um tipo de ocupação do espaço fortemente degradador do meio ambiente e expansivo sobre a floresta, o que determinou dois movimentos importantes: desmatamento e forte movimento migratório e de ocupação do binterland amazônico.

\subsubsection{A grande lavoura da soja no norte mato-grossense e a BR-163: as exportações do Mato Grosso e o avanço do desmatamento}

Como segundo maior exportador da Amazônia e terceiro do país em termos de saldo comercial, o Mato Grosso teve saldo comercial em 2010 de US $\$ 7,4$ bilhões, sendo cerca de US $\$ 8,4$ bilhões de exportação e quase US $\$ 1$ bilhão em importação.

As exportações mato-grossenses são compostas por mais de $90 \%$ de produtos básicos, dos quais a soja é o principal (quase 40\%). Os três primeiros da lista - soja, bagaço e outros resíduos sólidos e milho - somam cerca de $73 \%$ da pauta de exportação dessa unidade federativa (ver Tabela 3).

\footnotetext{
3 No período de 1990 a 1994, os dados referentes ao PIB regional não estão disponíveis para comparação em função de uma alteração metodológica ocorrida.
} 
Tabela 3. Principais produtos exportados pelo Estado do Mato Grosso (2010).

\begin{tabular}{lr}
\hline \multicolumn{1}{c|}{ Descrição NCM } & \multicolumn{1}{c}{ US\$ (mil) } \\
\hline Outros grãos de soja, mesmo triturados & 3.289 .963 \\
\hline Bagaços de outros resíduos sólidos da extração do óleo deesoja & 1.554 .501 \\
\hline Milho em grão, exceto para semeadura & 1.331 .708 \\
\hline Carnes desossadas de bovino, congeladas & 611.496 \\
\hline Algodão simplesmente debulhado, não cardado, não penteado & 399.776 \\
\hline Óleo de soja, em bruto, mesmo degomado & 256.574 \\
\hline Outros & 1.007 .355 \\
\hline Total & 8.451 .372 \\
\hline
\end{tabular}

Fonte: MDIC (2011).

O comportamento do setor exportador em Mato Grosso apresenta evolução surpreendente nos anos recentes. De 1998 a 2010, as exportações crescem ano após ano. Enquanto no primeiro ano o estado exportou US\$ 652 milhões, o valor em 2010 atingiu US\$ 8,4 bilhões, o que dá mais de 1000\% de variação. No que tange à soja, a China é o principal destino da produção no estado. Dos US \$ 3,2 bilhões exportados em soja em 2010, cerca de US\$ 2 bilhões foram de vendas para o país asiático (correspondentes a 5,4 milhões de toneladas do produto).

A cadeia produtiva da soja participa por volta de $20 \%$ do PIB do agronegócio nacional, correspondendo a mais de US $\$ 35$ bilhões no ano de 2004, e quase 50\% da colheita nacional estão nos estados do Mato Grosso e Paraná, que produziram respectivamente 14,5 e 10,2 milhões de toneladas no referido ano. Essa commoditie tem apresentado nas últimas duas décadas grande expansão em sua demanda internacional, o que se reflete em um comportamento do preço internacional extremamente regular, a despeito de uma crescente oferta dos produtores de três países-chave: Brasil, EUA e Argentina ${ }^{4}$.

A grande lavoura da soja tem um histórico de expansão rumo à fronteira norte brasileira bastante recente. Segundo Ferreira (1988), somente na segunda metade da década de 70 e mais criteriosamente no início dos anos 80 é que a lavoura temporária da soja implanta-se na região de cerrado do Estado de Goiás, isso favorecido por dois aspectos: a política do governo federal de polos de desenvolvimento (POLOCENTRO) e o asfaltamento da rodovia que liga a cidade de Rio Verde (GO) a Itumbira (MG).

4 O complexo da soja compreende uma cadeia produtiva, que envolve desde a produção interna voltada para a exportação do produto bruto, até a transformação do produto voltada para a indústria esmagadora que processa a soja em farelo ou óleo para a exportação ou para o consumo interno. Para a análise do complexo soja e sua importância para o agronegócio brasileiro, conferir Silva, Lima e Batista (2011). 
O rastilho que acompanha a expansão da soja caracteriza-se pela racionalidade que comanda esse tipo de produção, uma "tendência à concentração fundiária a níveis de tamanho médio e grande, inferiores aos dos grandes latifúndios pecuaristas", propriedades situadas entre "200 e 2000 ha”, muito mecanizada e utilizando somente sazonalmente força de trabalho. Em função dessas características, a expansão da lavoura de soja dá-se com um certo "despovoamento" do campo, contribuindo para o aumento da população urbana dos municípios da área de abrangência do "corredor da soja", ao mesmo tempo que a área desmatada cresce exponencialmente, como se verá a seguir.

A incorporação de terras agriculturáveis do Estado de Mato Grosso ao ciclo de acumulação da soja somente se dá no final da década de 80. Diferentemente de outras frentes de ocupações que foram patrocinadas pelo governo federal, no caso do Mato Grosso, a colonização foi, principalmente, dirigida por projetos privados, controlados por empresas de colonização paulistas ou paranaenses. Conforme Léna (1988), os colonos que ali se instalaram tinham um nível de capitalização superior ao dos que foram introduzidos nas frentes pioneiras do Pará e Rondônia, o que favoreceu logo no início um certo ordenamento no processo de ocupação.

O aumento do preço da soja no mercado internacional desencadeou a concentração de terras também no meio oeste mato-grossense e estimulou a penetração dessa cultura no norte daquele estado, já na fronteira com o Estado do Pará. A elevada taxa de crescimento da produção de soja pode ser visualizada no Gráfico 1.

Gráfico 1. Quantidade produzida de soja (tonelada).

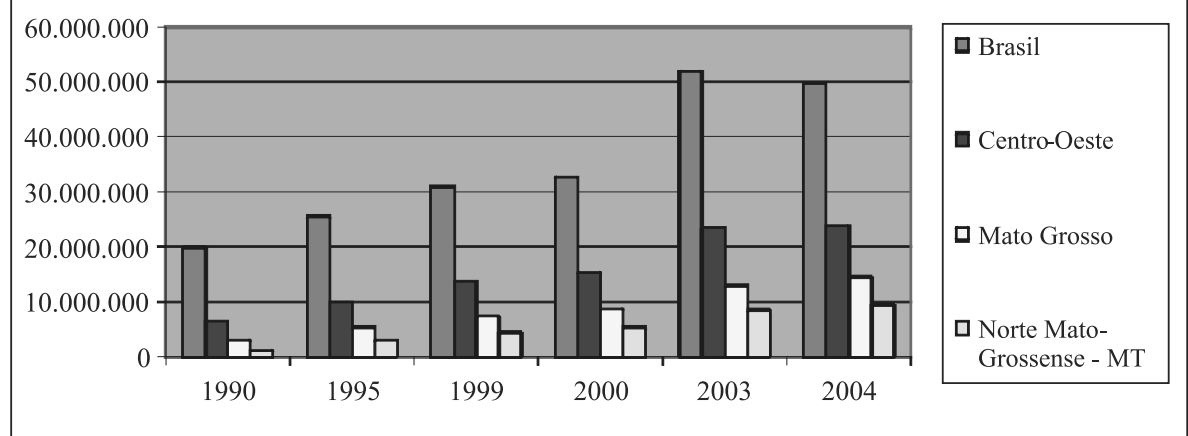

Fonte: IBGE (2011).

$5 \quad$ Ferreira (1988, p. 56) observa que, mesmo a lavoura comercial sendo mecanizada e poupadora de mão de obra, "estoca essa mão-de-obra para ocupar só em certas épocas do ano: na colheita e no preparo da terra. O trabalhador rural tornado assalariado e urbanita, a força de expulsão do campo, fica nas cidades próximas, formando o exército agrícola de reserva". 
O norte mato-grossense passa por uma rápida expansão na área plantada por soja. Segundo dados da Produção Agrícola Municipal (PAM), divulgados pelo Instituto Brasileiro de Geografia e Estatística (IBGE), a área total destinada a esse cultivo passa de cerca de 700 mil hectares em 1990, para algo em torno de 3,5 milhões de hectares plantados em 2004, uma taxa média de crescimento geométrica de $48,75 \%$.

Um aspecto importante a ser observado da expansão agrícola nessa região é que se trata, em grande medida, de uma estrutura bastante capitalizada, vinculada, inclusive, a tradings exportadoras, como a Cargill e a ADM, baseada em médios e grandes produtores, com um grau de produtividade e custos de produção próximos aos dos produtores paranaenses.

A estrutura fundiária tem se alterado na última década, e as principais cidades da região concentram-se nas proximidades da BR-163, constituindo, na sua maior parte, núcleos extremamente recentes - claro sinal do expressivo movimento migratório ocorrido na região, ao lado da característica já observada em outras áreas, do declínio da densidade demográfica no meio não urbano, desempenhando essas pequenas cidades o papel de pontos de apoio logístico e de disponibilidade de força de trabalho para a grande lavoura da soja.

Vale observar que o crescimento demográfico dessas cidades é muito intenso durante a fase de formação (ver Tabela 4), cuja característica principal é um intenso fluxo migratório, que rapidamente se estabiliza e se faz sentir em um novo núcleo populacional que se forma mais além.

Tabela 4. População e taxa média de crescimento anual (municípios do Mato Grosso adjacentes à BR-163).

\begin{tabular}{l|r|r|r|r|r|r|r}
\hline Locais & $\mathbf{1 9 8 0}$ & $\mathbf{1 9 9 1}$ & $\begin{array}{r}\mathbf{1 9 9 1 /} \\
\mathbf{1 9 8 0} \mathbf{( \% )}\end{array}$ & $\mathbf{2 0 0 0}$ & $\begin{array}{r}\mathbf{2 0 0 0 /} \\
\mathbf{1 9 9 1} \mathbf{( \% )}\end{array}$ & $\mathbf{2 0 1 0}$ & $\begin{array}{r}\mathbf{2 0 1 0 /} \\
\mathbf{2 0 0 0} \mathbf{( \% )}\end{array}$ \\
\hline Sinop & 19.766 & 73.096 & 24,52 & 74.831 & 0,26 & 113.099 & 5,11 \\
\hline Sorriso & - & 16.109 & - & 35.605 & 13,44 & 66.521 & 8,68 \\
\hline Alta Floresta & 22.919 & 66.928 & 17,45 & 46.982 & $-3,31$ & 49.164 & 0,46 \\
\hline Diamantino & 14.144 & 16.618 & 1,59 & 18.580 & 1,31 & 20.341 & 0,95 \\
\hline Nova Mutum & - & 5.543 & - & 13.606 & 16,16 & 31.649 & 13,26 \\
\hline $\begin{array}{l}\text { Lucas do Rio } \\
\text { Verde }\end{array}$ & - & 6.691 & - & 19.316 & 20,96 & 45.556 & 13,58 \\
\hline $\begin{array}{l}\text { Guarantã do } \\
\text { Norte }\end{array}$ & - & 23.821 & - & 28.200 & 2,04 & 32.216 & 1,42 \\
\hline Mato Grosso & 1.138 .691 & 2.026 .070 & 7,08 & 2.504 .353 & 2,6 & 3.035 .122 & 2,12 \\
\hline
\end{tabular}

Fonte: IBGE (Censos de 1980, 1991, 2000 e 2010). 
A explicação mais óbvia para a expansão da soja em Mato Grosso encontrase no preço da terra e no longo ciclo de crescimento da demanda da soja, que tem proporcionado uma grande regularidade nos seus preços internacionais.

O processo de expansão produtiva do agronegócio consolida um quadro de avançada substituição da floresta (e do cerrado) pela plantation, e a frente de expansão mais recente é a que se forma nas bordas dos dois estados (Mato Grosso e Pará) e parece configurar o principal fator a ser analisado de modificações no curto e médio prazo para a região do entorno da BR-163 até o município de Santarém, no Estado do Pará 6 .

\subsection{A QUESTÃO AMBIENTAL}

Destaca-se aqui basicamente a questão do desmatamento na Amazônia. Não é intenção adentrar nos detalhes, mas enfatizar alguns pontos relacionados com o setor exportador. A literatura sobre o assunto traz como informação básica que a pecuária é a principal responsável direta pelo desmatamento na região amazônica. Além da referida atividade, há também destaque para outras variáveis, como a abertura das estradas nos anos 70 e 80 (como determinante para os futuros padrões de desmatamento) e, em período mais recente, o crescimento considerável da plantação de soja (ALENCAR et al., 2004; FEARNSIDE, 2005, 2006; MARGULIS, 2003; RIVERO et al., 2009; SILVA et al., 2008; SOARESFILHO et al., 2005; YOUNG, 1998).

A Tabela 5 (abaixo) mostra o desmatamento anual por estado amazônico. Pará e Mato Grosso foram os que mais desmataram entre os anos 2000 e 2010, somando 130 mil km² de florestas derrubadas no período (de todos os estados foram quase $183 \mathrm{mil} \mathrm{km}^{2}$ ). Tal área desmatada pelos dois estados é maior do que o somatório das extensões territoriais da Paraíba, do Rio Grande no Norte e de Sergipe.

6 Theis (2009) e Costa (2004) definem, desde aportes teóricos distintos, diferentes combinações para trajetória de expansão produtiva do agronegócio na Amazônia, o que no entendimento do primeiro se estabelece no princípio de que a "conformação geográfica do capitalismo serve tanto para desenvolver o sistema quanto para questioná-lo e, quiçá, superá-lo" (THEIS, 2009, p.242), portanto o avanço do agronegócio na Amazônia combina contraditoriamente avanço do capital e aprofundamento do próprio questionamento ao modelo. Costa (2004, p. 154), por sua vez, pondera que a construção de "uma institucionalidade que vise a sustentabilidade dos usos da base natural da região (...) constituirá uma referência necessária a um desenvolvimento de novo tipo", o que está relacionado a diferentes "trajetórias" de exploração econômica do bioma amazônico. 
Tabela 5. Taxa de desmatamento anual na Amazônia (km²/ano), 2000-2010.

\begin{tabular}{l|r|r|r|r|r|c|r|r|r|r}
\hline Ano & \multicolumn{1}{c|}{ AC } & \multicolumn{1}{c|}{ AM } & AP & \multicolumn{1}{c|}{ MA } & MT & PA & RO & RR & TO & Amazônia \\
\hline 2000 & 547 & 612 & - & 1.065 & 6.369 & 6.671 & 2.465 & 253 & 244 & 18.226 \\
\hline 2001 & 419 & 634 & 7 & 958 & 7.703 & 5.237 & 2.673 & 345 & 189 & 18.165 \\
\hline 2002 & 883 & 885 & 0 & 1.085 & 7.892 & 7.510 & 3.099 & 84 & 212 & 21.651 \\
\hline 2003 & 1.078 & 1.558 & 25 & 993 & 10.405 & 7.145 & 3.597 & 439 & 156 & 25.396 \\
\hline 2004 & 728 & 1.232 & 46 & 755 & 11.814 & 8.870 & 3.858 & 311 & 158 & 27.772 \\
\hline 2005 & 592 & 775 & 33 & 922 & 7.145 & 5.899 & 3.244 & 133 & 271 & 19.014 \\
\hline 2006 & 398 & 788 & 30 & 674 & 4.333 & 5.659 & 2.049 & 231 & 124 & 14.286 \\
\hline 2007 & 184 & 610 & 39 & 631 & 2.678 & 5.526 & 1.611 & 309 & 63 & 11.651 \\
\hline 2008 & 254 & 604 & 100 & 1.271 & 3.258 & 5.607 & 1.136 & 574 & 107 & 12.911 \\
\hline 2009 & 167 & 405 & 70 & 828 & 1.049 & 4.281 & 482 & 121 & 61 & 7.464 \\
\hline 2010 & 273 & 474 & 0 & 679 & 828 & 3.710 & 427 & 0 & 60 & 6.451 \\
\hline
\end{tabular}

Fonte: INPE (2011).

Os primeiros anos da década passada foram críticos em termos de devastação florestal na Amazônia, que atingiu, em 2004, 27,7 mil km² de área desmatada. Naquele ano, só o Estado do Mato Grosso foi responsável por mais de $40 \%$ do desmatamento total, seguido pelo Pará (32\%). A partir desse pico, a área tem diminuído gradativamente, alcançando 6,4 mil $\mathrm{km}^{2}$ de área desmatada em 2010, o que ainda é muito elevado.

Preocupa a observação de que os produtos responsáveis pelo desmatamento são justamente os que estão em maior ascensão na pauta exportadora. E a Amazônia fornece boa parte deles, com destaque para a pecuária bovina (carne e até boi vivo) e a soja.

Especificamente no caso da soja, o acompanhamento geoespacial feito pelo Instituto Nacional de Pesquisas Espaciais (INPE) há muito demonstrou a forte correlação entre as frentes de expansão produtiva e o forte incremento da floresta desmatada, em geral, a soja aparece como segunda geração de ocupação e alteração entrópica, após a expansão pecuária e a exploração madeireira.

No caso da extração mineral, o forte discurso ambientalista das principais empresas do setor contrasta com seu efetivo padrão devastador. Vale observar que o ciclo minerador completo constitui-se de três fases: i) o desmanche florestal, com a remoção dos maciços florestais nas áreas a serem mineradas; ii) a extração da laterita e a exposição da jazida mineral; iii) o abandono da área atual e a abertura de nova frente. Em alguns casos, as empresas mineradoras reconstituem uma floresta secundária, porém com enorme perda de diversidade.

O impacto comum a essas duas principais frentes de produção extrativa e agroexportadoras refere-se aos intensivos processos migratórios e de constituição 
de núcleos citadinos, que produzem efeitos derivados do desmate e do uso das florestas, além de padrões sociais bastante adversos, característicos de fronteiras de expansão da acumulação capitalista.

\section{CONTABILIDADE AMBIENTAL VERSUS CONTABILIDADE EXPORTADORA}

A explanação desenvolvida nas seções anteriores serviu para mostrar a composição da pauta de exportação da Amazônia (destacando-se o Pará e o Mato Grosso) e do Brasil. Agora, as exportações são observadas por fator agregado, analisando-se o comportamento das vendas dos produtos básicos e industrializados da Amazônia e do Brasil.

Constata-se, então, para o Brasil, que, em termos absolutos, a exportação de produtos industrializados ainda é maior que a de básicos, porém esta última tem crescido e aumentado sua participação relativa a cada ano na pauta de exportação do país, com notórias implicações macroeconômicas quanto aos aspectos de apreciação cambial e trajetória de possível desindustrialização.

A Tabela 6 mostra os percentuais de produtos básicos e industrializados exportados pelo Brasil e a relação entre eles. Nota-se que, no começo da série, três quartos da exportação eram de produtos industrializados, chegando em 2010 a um percentual próximo a 50\%.

Os produtos básicos têm aumentado sua participação na pauta das exportações brasileiras, de tal modo que a relação básicos/industrializados é crescente ao longo do período. No primeiro ano da série, o índice foi de 0,31 , ou seja, em $1995^{7}$ os básicos representavam cerca de um terço dos industrializados. Ao longo dos últimos quinze anos, o índice tem-se elevado, chegando a 0,83 no último ano da série.

No caso da Amazônia, esse coeficiente é ainda mais dramático, pois a pauta de exportação é mais significativamente centrada em bens básicos. O Gráfico 2 mostra que, até o ano de 2003, a relação básicos/industrializados para a Amazônia era menor que 1, o que significava que os produtos industrializados representavam parcela maior das exportações. A partir de 2004, percebe-se uma inversão, quando as vendas ao exterior de produtos básicos aumentam sua participação, de tal forma que a relação básicos/industrializados no ano de 2010 chegou a 3,12, ou seja, mais do triplo de exportação dos básicos em relação aos industrializados.

\footnotetext{
Boa parte das séries aqui utilizadas começa em 1995. A motivação para tal escolha é trabalhar com dados a partir da implantação do Plano Real (para que mesmo os valores das transações tenham o dólar como unidade monetária).
} 
Tabela 6. Percentual de produtos básicos e industrializados exportados pelo Brasil e relação básicos/industrializados (1995-2010).

\begin{tabular}{l|c|c|c}
\hline Ano & \%_básicos & \%_indust. & básicos/indust. \\
\hline 1995 & 23,59 & 75,08 & 0,31 \\
\hline 1996 & 24,92 & 73,74 & 0,34 \\
\hline 1997 & 27,32 & 71,16 & 0,38 \\
\hline 1998 & 25,37 & 73,34 & 0,35 \\
\hline 1999 & 24,63 & 73,55 & 0,33 \\
\hline 2000 & 22,79 & 74,49 & 0,31 \\
\hline 2001 & 26,33 & 70,69 & 0,37 \\
\hline 2002 & 28,06 & 69,55 & 0,40 \\
\hline 2003 & 28,94 & 69,27 & 0,42 \\
\hline 2004 & 29,51 & 68,86 & 0,43 \\
\hline 2005 & 29,30 & 68,61 & 0,43 \\
\hline 2006 & 29,23 & 68,61 & 0,43 \\
\hline 2007 & 32,12 & 65,82 & 0,49 \\
\hline 2008 & 36,89 & 60,50 & 0,61 \\
\hline 2009 & 40,63 & 57,55 & 0,71 \\
\hline 2010 & 44,65 & 53,48 & 0,83 \\
\hline
\end{tabular}

Fonte: MDIC (2011).

Elaboração dos autores.

Gráfico 2. Relação básicos/industrializados de produtos exportados pela Amazônia e pelo Brasil (1995-2010).

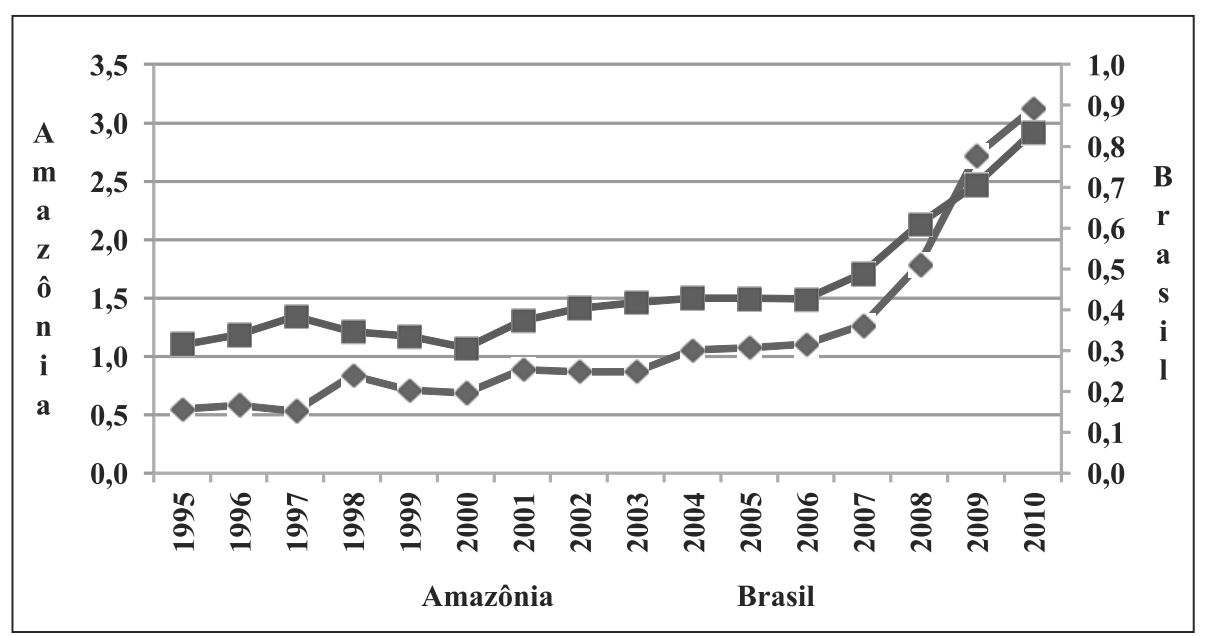

Fonte: MDIC (2011).

Elaboração dos autores. 
Enfatizando-se apenas a exportação de produtos básicos, a dinâmica exportadora revela que a Amazônia dobrou sua participação no fornecimento nacional de produtos de menor valor agregado de 1995 para cá. A Tabela 7 mostra que, no começo da série, a região amazônica era responsável por cerca de $10 \%$ da exportação nacional de produtos básicos. No final da década de 90 , o percentual já apresenta aumento expressivo, atingindo o pico em 2009, com 23,2\%. Verifica-se, então, que quase um quarto de toda a exportação nacional de produtos básicos tem origem na Amazônia.

Tabela 7. Exportações de produtos básicos pela Amazônia e pelo Brasil (1995-2010).

\begin{tabular}{l|c|c|c}
\hline & & \multicolumn{2}{|c}{ US\$ Mil (FOB) } \\
\hline Ano & Amazônia & Brasil & \%_Amazônia \\
\hline 1995 & 1.111 .264 & 10.968 .643 & 10,13 \\
\hline 1996 & 1.150 .058 & 11.900 .127 & 9,66 \\
\hline 1997 & 1.177 .072 & 14.473 .806 & 8,13 \\
\hline 1998 & 1.763 .530 & 12.976 .630 & 13,59 \\
\hline 1999 & 1.687 .334 & 11.827 .714 & 14,27 \\
\hline 2000 & 2.078 .022 & 12.564 .214 & 16,54 \\
\hline 2001 & 2.433 .090 & 15.349 .157 & 15,85 \\
\hline 2002 & 2.739 .186 & 16.959 .138 & 16,15 \\
\hline 2003 & 3.281 .494 & 21.186 .281 & 15,49 \\
\hline 2004 & 4.923 .374 & 28.528 .571 & 19,46 \\
\hline 2005 & 6.758 .530 & 34.723 .705 & 19,45 \\
\hline 2006 & 7.833 .855 & 40.280 .500 & 18,48 \\
\hline 2007 & 9.535 .675 & 51.595 .635 & 20,76 \\
\hline 2008 & 15.157 .183 & 73.027 .660 & 23,21 \\
\hline 2009 & 14.427 .068 & 62.156 .087 & 22,20 \\
\hline 2010 & 20.014 .744 & 90.147 .293 & \\
\hline
\end{tabular}

Fonte: MDIC (2010).

Elaboração dos autores.

O cenário amazônico e o nacional, portanto, evidenciam um acelerado processo de especialização primária da pauta de exportação, com consideráveis implicações tanto econômicas quanto socioambientais, consistindo o desmatamento em um das principais decorrências. Vale, portanto, tratar mais detidamente, das consequências para a Amazônia e para o Brasil.

A geração de divisas por via da balança comercial em anos recentes está pautada principalmente pela comercialização de produtos básicos. Mais ainda, 
a balança comercial no país deve e muito sua situação superavitária aos estados da Amazônia, principalmente Pará e Mato Grosso. Logo, a Amazônia é uma importante região para o Brasil.

Porém, o custo do movimento observado de deslocamento da produção para produtos básicos é elevado. Em termos nacionais, o crescimento da especialização primária tem o poder de provocar o fenômeno conhecido como "doença holandesa". Em suma, o maior volume exportado de commodities em detrimento de produtos manufaturados tende a apreciar a taxa de câmbio, prejudicando a indústria nacional. É o que está ocorrendo atualmente no Brasil'

Outro fator negativo é a questão regional. Manter a tendência rumo à conversão da Amazônia em grande celeiro de produtos primários certamente não ajudará na busca pela diminuição das desigualdades regionais no país. Pelo contrário.

As condições de desenvolvimento regional parecem ainda mais agravadas pela relação contraditória entre desoneração da exportação e exportação de bens primários e semielaborados. A contradição presente relaciona-se a dois aspectos centrais: i) as cadeias de produção primário-exportadoras são muito curtas, o que estabelece a incapacidade de apropriação de rendas (mineradoras ou agrárias) que pudessem definir novos padrões sociais e ambientais para a região; ii) a segunda contradição relaciona-se bastante com a anterior e refere-se à desoneração tributária para a exportação desse tipo de bem estabelecida pela Lei Complementar n. ${ }^{\circ}$ 87/96 (Lei Kandir), sem contudo nenhuma solução federativa ser oferecida. Os estados exportadores líquidos acabam tendo o ônus ambiental e social, sem o devido retorno, seja tributário, seja oriundo de acordo federativo.

Mantendo a tendência observada de ser grande fornecedor de produtos básicos, a região: i) perde por não agregar valor ao processo produtivo; ii) aumenta sua fragilidade em possíveis crises no mercado externo (ou queda nos preços por algum outro motivo), dada a ênfase na exportação de commodities; iii) aumenta o gap no processo de desenvolvimento regional em relação às outras regiões do país, que se voltam mais para a produção industrial; iv) perde também por apresentar maior concentração de capital (e renda) no setor primário-exportador, que não proporciona efeito transbordamento na economia; v) em termos ambientais, o prejuízo também é grande, pois as atividades tidas como principais causadoras do desmatamento (mineração, pecuária e soja) estão na cesta de exportação crescente dos produtos primários.

Assim, o trade-off geração de divisas versus recrudescimento da desigualdade produtiva regional deve ser repensado, seja pela necessária melhoria da qualidade

\footnotetext{
Ver Bresser-Pereira (2008).

9 Ver Bresser-Pereira (2007).
} 
de vida da população da região amazônica, seja pela introdução de um modelo de desenvolvimento que supere o atual padrão de mero celeiro de produtos básicos, com efeitos deletérios crescentes sobre o meio ambiente e com baixo retorno social - basta conferir os indicadores de desenvolvimento humano da região e especialmente dos dois estados em foco.

Se depender do mercado externo, esse cenário poderá intensificar-se, pois a demanda internacional por minério de ferro, soja e carne bovina permanece crescente e não apresenta sinais de mudança. Continuando a China com suas elevadas taxas de crescimento, assim como a recuperação econômica dos Estados Unidos e dos países europeus, a tendência é que o Brasil continue ampliando seu papel de fornecedor mundial dos produtos citados e tenha sua pauta de exportação cada vez mais centrada em produtos básicos.

\section{CONSIDERAÇÕES FINAIS}

A geração de divisas por meio da balança comercial em anos recentes está baseada principalmente na comercialização de produtos básicos. Mais ainda, a balança comercial no país deve e muito sua situação superavitária aos estados da Amazônia, principalmente Pará e Mato Grosso. A Amazônia é, portanto, uma importante região exportadora para o Brasil.

A contradição apontada neste estudo pode ser mais bem visualizada na citação que retiramos do Plano Amazônia Sustentável (PAS), que contempla as diretrizes gerais para as ações estruturantes de desenvolvimento para a região constantes no PPA 2008-2011. O PAS tem como objetivo principal:

[...] a promoção do desenvolvimento sustentável da Amazônia brasileira, mediante implantação de novo modelo pautado na valorização de seu enorme patrimônio natural e no aporte de investimentos em tecnologia e infraestrutura, voltado para a viabilização de atividades econômicas dinâmicas e inovadoras com a geração de emprego e renda, compatível com o uso sustentável dos recursos naturais, preservação de biomas e visando a elevação do nível de vida da população (BRASIL, 2008, p. 55).

Por tudo o que foi desenvolvido ao longo do texto, fica bastante evidente a complexa questão envolvida: se de um lado o discurso ambientalista sufraga a necessidade de um "novo modelo", por outro a dura crueza do balanço de pagamentos e das necessidades de geração de divisas impõe a continuidade e a expansão do velho modelo primário-exportador - em termos bastante agudos, muito pouco preocupado com a preservação de biomas ou com a elevação da qualidade de vida das populações autóctones. 


\section{REFERÊNCIAS}

ALENCAR, A. Desmatamento na Amazônia: indo além da "emergência crônica". Belém: IPAM, 2004.

BECKER, B. K. Dinâmica urbana na Amazônia. In: DINIZ, Clélio C.; LEMOS, Mauro

B. (Org.). Economia e território. Belo Horizonte: UFMG, 2005. p. ...-...

BELLUZZO, L. G.; ALMEIDA, J. G. de. O mergulho da indústria. CartaCapital, São Paulo, 22 de junho de 2011. Disponível em <http://www.cartacapital.com.br>. Acesso em:

BRASIL. Ministério do Meio Ambiente. Plano Amazônia Sustentável: diretrizes para o desenvolvimento sustentável da Amazônia brasileira. Brasília, DF, 2008. BRASIL. Ministério do Desenvolvimento, Indústria e Comércio Exterior. Sistema AliceWeb. Disponível em: < http:/ / aliceweb.desenvolvimento.gov.br/>. Acesso em: 19 maio 2011.

BRESSER-PEREIRA, L. C. Desindustrialização e doença holandesa. Folha de S.Paulo, São Paulo, 9 abr. 2007. Disponível em <http://www.bresserpereira.org.br/ view.asp? cod=2307>. Acesso em: 2 jun. 2011.

The Dutch disease and its neutralization: a Ricardian approach. Brazilian Journal of Political Economy, v. 28, n. 1, p. 47-71, Jan./Mar. 2008.

BRITO, Daniel Chaves de. A Sudam e a crise institucional do desenvolvimento na Amazônia. Belém: NAEA, 1998 (Paper do NAEA, n. 96).

BUNKER, S. G. Os fatores espaciais e materiais da produção e os mercados globais. Novos Cadernos NAEA, Belém, v. 7, n. 2, p. 67-107, dez. 2004.

CASTRO, E. R. de. Estado e políticas públicas na Amazônia em face da globalização e da integração de mercados. In: COELHO, Maria C. N. et al. (Org.). Estado e políticas públicas na Amazônia: gestão do desenvolvimento regional. Belém: Cejup, 2001. p. ...-...

FEARNSIDE, P. M. Desmatamento na Amazônia brasileira: história, índices e conseqüências. Megadiversidade, v. 1, n. 1, p. 113-123, jul. 2005.

Desmatamento na Amazônia: dinâmica, impactos e controle. Acta Amazonica, v. 36, n. 3, p. 395-400, 2006.

FERREIRA, I. C. B. Ceres e Rio Verde: dois momentos da expansão da fronteira agrícola. In: AUBERTIN, Catherine (Org.). Fronteiras. Brasília, DF: UNB; Paris: ORSTOM, 1988. p. 415-458.

INSTITUTO BRASILEIRO DE GEOGRAFIA E ESTATÍSTICA. Pesquisa Agrícola Municipal. Disponível em: < http://www.sidra.ibge.gov.br/>. Acesso em: 7 jun. 2011. 
INSTITUTO BRASILEIRO DE GEOGRAFIA E ESTATÍSTICA. Censo Demográfico (vários anos). Disponível em: <http:/ / www.ibge.gov.br>. Acesso em: 10 jun. 2011.

INSTITUTO NACIONAL DE PESQUISAS ESPACIAIS. Prodes - desflorestamento nos municípios da Amazônia Legal. Disponível em: < http://www.dpi.inpe.br/ prodesdigital/prodesmunicipal.php>. Acesso em: 21 maio 2011.

LEAL, A. L. Uma sinopse histórica da Amazônia (uma visão política). In: TRINDADE, J. R. B.; MARQUES, G. (Org.). Revista de Estudos Paraenses (edição especial). Belém: IDESP, 2010. p. ...-...

LÉNA, P. Diversidade da fronteira agrícola na Amazônia. In: AUBERTIN, Catherine (Org.). Fronteiras. Brasília, DF: UnB; Paris: ORSTOM, 1988. p. 90-129.

MARGULIS, S. Causas do desmatamento da Amazônia Brasileira. Brasília, DF: Banco Mundial, 2003.

MARQUES, G. de S. Estado e desenvolvimento na Amazônia: inclusão amazônica na reprodução capitalista brasileira. 2007. ... f. Tese (Doutorado em Desenvolvimento, Agricultura e Sociedade) - Universidade Federal Rural do Rio de Janeiro, Rio de Janeiro, 2007.

MENDES, A. D. Introdução ao planejamento regional brasileiro. Salvador: Instituto de Economia e Finanças da Bahia, 1958, v. 1.

PANDOLFO, C. Amazônia Brasileira: ocupação, desenvolvimento e perspectivas atuais. Belém: CEJUP, 1994.

RIVERO, S.; ALMEIDA, O.; ÁVILA, S.; OLIVEIRA, W. Pecuária e desmatamento: uma análise das principais causas diretas do desmatamento na Amazônia. Nova Economia, Belo Horizonte, v. 19, n. 1, p. 41-66, 2009.

SANTOS, R. História econômica da Amazônia (1800-1920). São Paulo: T. A. Queiroz, 1980.

SILVA, A. C. da; LIMA, Érica Priscilla Carvalho de; BATISTA, Henrique Rogê. A importância da soja para o agronegócio brasileiro: uma análise sob o enfoque da produção, emprego e exportação. 2011. Disponível em: <http:/ /www.apec.unesc. net>. Acesso em: 4 jan. 2012.

SOARES-FILHO, B. S. et al. Cenários de desmatamento para a Amazônia. Estudos Avançados, São Paulo, v. 19, n. 54, p. 137-152, maio/ago. 2005.

TRINDADE, J. R. B. A metamorfose do trabalho na Amazônia: para além da Mineração Rio do Norte. Belém: UFPA, NAEA, 2001. 171 p.

YOUNG, C. E. F. Public policies and deforestation in the Brazilian Amazon. Planejamento e Políticas Públicas, Brasília, DF, n. 18, p. 201-222, dez. 1998. 